\title{
CARACTERÍSTICAS COMUNS À NARRATIVA ORAL DE CRIANÇAS NA PRÉ-ALFABETIZAÇÃO
}

\section{Common characteristics of verbal narratives of children in pre-literacy}

\author{
Eliane Varanda Dadalto ${ }^{(1)}$, Márcia Goldfeld (2)
}

\begin{abstract}
RESUMO
Objetivo: analisar aspectos constitutivos das narrativas de histórias e relatos em crianças de 5 e 6 anos. Métodos: participaram deste estudo 50 crianças, de ambos os sexos, sendo 23 meninos e 27 meninas das classes de pré-alfabetização de quatro Escolas Particulares da Praia do Canto, bairro de classe média alta da cidade de Vitória-Espírito Santo. A amostra foi constituída da narrativa de uma história e de um relato, numa interação informal em que foi solicitada à criança que narrasse a história de "Chapeuzinho Vermelho", por ser uma história das mais conhecidas, e fizesse um relato de uma situação vivida. Os critérios de análise foram baseados em Perroni (1992) e em Brandão e Spinillo (2001). Resultados: a população apresentou conhecimento da estrutura da narrativa; domínio satisfatório da relação temporal entre eventos narrados; utilização de orações que expressam a dependência temporal com verbos de ação no pretérito (perfeito e imperfeito); utilização de operadores narrativos com predominância de "aí" e "depois"; utilização de pontos de referência temporal e espacial com propriedade; relações espaço-temporais bem organizadas e as causais em fase de estruturação. Apontou, ainda, a importância da participação do interlocutor na construção das narrativas. Conclusão: as crianças apresentaram maior facilidade na produção da história que no relato; respondem a todo tipo de pergunta eliciadora; a maior parte precisou de mediação apenas no relato; respeitam a seqüência temporal tanto na história, usando as figuras da história de maneira correta, quanto no relato e utilizam principalmente o "aí" como elemento de coesão causal e temporal.
\end{abstract}

DESCRITORES: Narração; História; Linguagem; Criança

\section{INTRODUÇÃO}

Nas últimas décadas, pesquisadores das mais diversas áreas têm mostrado interesse pelo estudo das narrativas e, em especial, por sua estrutura ${ }^{1}$ e muitos desses estudos registram a importância do desenvolvimento das narrativas no processo de desenvolvimento do discurso oral e da escrita ${ }^{2-8}$.

Tais trabalhos apresentaram 0 assunto sob abordagens teóricas diferentes, entre os quais, em maior número, apareciam os cognitivistas e os sociointeracionistas e, dentre eles, destaca-se um estudo nacional ${ }^{9}$ com pressupostos discursi-

(1) Fonoaudióloga; Professora do Curso de Fonoaudiologia do Centro Universitário Vila Velha, ES; Mestre em Fonoaudiologia pela Universidade Veiga de Almeida.

(2) Fonoaudióloga; Professora Adjunta do Mestrado Profissionalizante em Fonoaudiologia da Universidade Veiga de Almeida, UVA, Rio de Janeiro, RJ; Professora Adjunta do Curso de Fonoaudiologia da Universidade Federal do Rio de Janeiro, UFRJ, Rio de Janeiro, RJ; Doutora em Distúrbios da Comunicação Humana pela Universidade Federal de São Paulo. vos, valorizando situações interacionais e relações dialógicas como constitutivas da narrativa infantil tendo,assim, adulto e criança, papéis ativos.

Estudos realizados com crianças de quatro a oito anos mostraram que a habilidade de narrar é adquirida gradativamente ${ }^{10,11}$, não sendo uma tarefa muito simples de ser realizada visto que implica considerar o outro como interlocutor e considerarse como narrador. Alguns dos estudos destacam resultados em que se verificou que, com o aumento da idade e da escolaridade, a narrativa de histórias tornava-se mais complexa e elaborada ${ }^{6-15}$. Assim, evidencia-se que existe uma evolução quanto ao domínio das convenções e da estrutura próprias da contagem de história.

O discurso narrativo representa, na experiência linguística oral da criança, uma (e talvez a mais importante) passagem obrigatória do diálogo para o monólogo para a construção de um texto cuja significação pode representar a culminação de um processo em que a criança atinge uma maior autonomia discursiva ${ }^{8}$. 
Narrar serve a necessidades cognitivas, estruturando e processando a experiência pessoal e necessidades sociais, compartilhando tais experiências ${ }^{16}$.

Um estudo longitudinal, voltado para o desenvolvimento do discurso narrativo de duas crianças brasileiras de classe socioeconômica média, entre dois e cinco anos, em ambiente familiar realizado na década de $80^{9}$ permitiu reconhecer as características de estruturas narrativas nas diferentes fases do desenvolvimento. Nesse trabalho, a autora põe em foco o que ela própria chama de "visão processual do desenvolvimento"; valoriza a criança como um ser ativo na relação diádica; enfatiza o papel do adulto na interação, no diálogo, enfim, no processo de desenvolvimento do discurso narrativo.

Constatou-se ainda, assim como autores em outros trabalhos ${ }^{9,13,14,16-18}$, que o adulto tem importante papel na construção do discurso infantil, assumindo turnos de interação com a criança por meio de perguntas chamadas eliciadoras, quando a criança ainda não tem domínio de seu discurso.

Outra autora ${ }^{19}$ chama atenção para o papel da interação social na aquisição da estrutura narrativa e para as diferenças culturais que se refletem no estilo conversacional. Alguns estudos ${ }^{4,17,20}$ ainda correlacionam o estilo conversacional dos pais com o desempenho narrativo das crianças, mostrando como um estilo que envolva mais perguntas e comentários pode favorecer o desenvolvimento do discurso narrativo das crianças. Esses mesmos autores em outro trabalho reforçam estudo anterior mostrando como é possível ensinar os pais a interagirem com seus filhos de forma mais produtiva no que diz respeito ao desenvolvimento da narrativa, ensinando-os a conversar com os filhos frequentemente; enfatizando questões contextuais do evento; ouvindo atentamente à criança; encorajando a criança a falar mais, dando respostas de feedback ou repetindo a fala da criança; conversando sobre tópicos do interesse da criança.

Muitos dos estudos que vêm sendo realizados acerca do desenvolvimento da narrativa de histórias em crianças têm considerado determinados padrões de construção para a análise que levam em conta a estrutura de elementos identificados e formalizados nas gramáticas de histórias. Por exemplo: a) início com uma abertura convencional (introdução da cena: informações sobre o tempo e lugar; personagens: suas características, motivações e metas a alcançar); b) meio (evento, trama, situação-problema) e c) final (resolução da situação-problema) com um fechamento convencional.

Outro exemplo citado é a adaptação do sistema de categorias ${ }^{17,20-24}$ a partir de um estudo original. Essas categorias expressam diferentes níveis de desenvolvimento na aquisição de um esquema narrativo, e estão assim organizadas: I) produções que consistem em não-histórias por não apresentarem construções ou convenções próprias desse tipo de registro; II) introdução de cenas e personagens, com marcadores linguísticos convencionais de início de história (era uma vez etc.); III) histórias incompletas com estrutura narrativa elementar. Apresentam introdução da cena e dos personagens com início convencional e ainda a presença de uma ação que sugere o início de uma trama; IV) semelhante à categoria III, apresentando ainda um desfecho ou uma resolução da trama subitamente resolvida sem explicação dos meios utilizados para tal. Uso de marcadores convencionais de final de histórias e V) histórias completas com estrutura narrativa elaborada.

Constatando a importância do discurso oral para o desenvolvimento linguístico ${ }^{25}$, cognitivo e social da criança, sendo também base para o aprendizado da língua escrita, considera-se relevante conhecer a produção narrativa oral de crianças no momento imediatamente anterior à sua entrada na classe de alfabetização.

O objetivo do estudo foi analisar aspectos constitutivos das narrativas de histórias e relatos em crianças de 5 e 6 anos.

\section{MÉTODOS}

O trabalho foi realizado com 50 crianças, de ambos os sexos, sendo 23 meninos e 27 meninas com idade média de 5 anos, das classes de pré-alfabetização de quatro Escolas Particulares da Praia do Canto, bairro de classe média alta da cidade de Vitória-Espírito Santo. Os participantes foram selecionados pela escola obedecendo ao critério de desenvolvimento linguístico satisfatório, ou seja, não haver nenhuma queixa da família ou escola, quanto ao desenvolvimento e aprendizagem.

Foi coletada a narrativa de uma história e de um relato, numa interação informal entre a criança e a pesquisadora em que foi solicitada à criança que narrasse a história de "Chapeuzinho Vermelho", por ser uma história das mais conhecidas, e fizesse um relato de uma situação vivida. Os critérios de análise são os descritos no estudo longitudinal realizado na década de $80^{9}$ e o de categorias ${ }^{23}$. A análise quantitativa será demonstrada em tabelas para melhor visualização dos resultados.

A participação das crianças na pesquisa só ocorreu após a assinatura do Termo de consentimento, livre e esclarecido, de todos os responsáveis pelas crianças envolvidas, e autorização do Comitê de Ética em Pesquisa da Universidade Veiga de Almeida sob o no 41/05. 


\section{RESULTADOS}

As 50 crianças fizeram seus relatos em situação de diálogo e de monólogo, 22\% (11 crianças) em diálogo e 78\% (39 crianças) em monólogo. Cabe ressaltar que apenas uma criança usou todas as 16 figuras em um único monólogo.

É interessante notar que as figuras da história mais frequentes são aquelas determinantes ao desenvolvimento da história (Tabela 1). A criança elege os elementos da síntese com muita propriedade. Pelos resultados, a síntese ficaria mais ou menos assim: "A mãe pede a Chapeuzinho para levar os doces para a vovó. Ela encontra o lobo que a aborda. O lobo chega primeiro na casa da vovó, come a vovó e se veste com as roupas dela para esperar Chapeuzinho. Ela chega, conversam e o lobo ataca Chapeuzinho que recebe ajuda dos caçadores".

A existência de dependência temporal entre eventos é fato marcante e evidente em todas as narrativas. As crianças pesquisadas apresentaram todos esses critérios, a saber: a dependência temporal, orações que expressam essa dependência temporal constituída essencialmente por verbos de ação e o emprego do tempo perfeito. Ou seja, as crianças pesquisadas, antes de serem expostas à alfabetização formal, já dominavam satisfatoriamente a relação temporal entre eventos narrados.
Pela análise quantitativa, nota-se que os operadores narrativos convencionais de abertura e fechamento perdem importância para as crianças pesquisadas. Isso pode ser facilmente verificado no exemplo 1. É possível que isso se deva ao fato de as crianças hoje terem mais contato com filmes em cinema ou DVD, cujas histórias não começam com "Era uma vez", e menor contato com os livros clássicos de histórias.

\section{Exemplo 1:}

A mãe de Chapeuzinho Vermelho falou assim: 'Chapeuzinho, vem pra cá. Eu só tenho que levar uma cesta pra vovó, ela está doente'. Aí, aí é:: ela pegou a cesta, aí ela saiu com a cesta, aí ela saiu com a cesta e foi pra casa da vovó ( $T-5$ anos).

A manutenção dessa dependência se dá geralmente pelo marcador "ai" que, além de partilhar de algumas das funções de conectivo da conjunção " $e$ ", atuou como organizador da sequência narrativa, favoreceu a progressão do texto e contribuiu para a coesão sequencial, indicando sequências temporais e mudança de assunto. O conector "aí" pode ainda assumir duas funções: hesitação (o que falar?) e manutenção da fala (eu ainda estou falando) ${ }^{7}$. Verificam-se, nas narrativas analisadas, essas mesmas funções. O elemento de coesão "aí", sem dúvida, predominou na maior parte das narrativas de histórias (Tabela 2).

Tabela 1 - Classificação das ocorrências das figuras da história com base em 50 histórias analisadas

\begin{tabular}{lcc}
\hline FIGURAS DA HISTÓRIA CHAPEUZINHO VERMELHO & Ocorre & Não ocorre \\
\hline A mãe pede a Chapeuzinho para levar doce para a vovó & 45 & 5 \\
A vovó está doente (Por que ela foi levar doces para a vovó?). & 34 & 16 \\
A mãe orienta sobre o caminho a seguir & 35 & 15 \\
Chapeuzinho desobedece e vai pela floresta & 27 & 23 \\
O lobo aborda Chapeuzinho & 46 & 4 \\
O lobo a engana & 35 & 15 \\
O lobo chega primeiro à casa da vovó & 49 & 1 \\
O lobo imita Chapeuzinho & 26 & 24 \\
A vovó manda entrar & 22 & 28 \\
O lobo come a vovó (ou similar) & 47 & 3 \\
O lobo se fantasia de vovó & 47 & 3 \\
Chapeuzinho chega & 45 & 5 \\
Diálogo entre o lobo e Chapeuzinho & 45 & 5 \\
O lobo ataca Chapeuzinho & 41 & 9 \\
Os caçadores chegam (desfecho) & 49 & 1 \\
E foram felizes para sempre (fechamento convencional) & 16 & 34 \\
\hline
\end{tabular}


Tabela 2 - Uso de operadores narrativos. Classificação com base em 50 relatos analisados

\begin{tabular}{lcc}
\hline Operadores narrativos & $\begin{array}{c}\text { História } \\
\text { no de vezes }\end{array}$ & $\begin{array}{c}\text { Relato } \\
\text { no de vezes }\end{array}$ \\
\hline "Aí" & 551 & 152 \\
"Então" & 1 & 1 \\
"Depois" & 92 & 48 \\
"Antes" & 3 & 2 \\
"Sabe?" & 1 & 6 \\
"Num tem?" & - & 4 \\
"Daí" & - & 1 \\
Como é que se diz? & - & 1 \\
\hline
\end{tabular}

No exemplo 2, além do aparecimento do conectivo "aí" e "depois", também podemos notar a presença de "primeiro", que aparece organizando, ordenando os acontecimentos.

\section{Exemplo 2:}

Era uma vez Chapeuzinho Vermelho. Aí ela foi lá passear e encontrou um lobo. Aí o lobo falou: 'Vão ver quem chega primeiro na casa da sua avó?'. Aí ele chegou primeiro e depois, aí ele comeu a avó e depois deitou na cama da vó e fez é:::: Fingiu que ele foi a vó. Aí a Chapeuzinho chegou e.:.: (silêncio) aí ela bateu na porta e aí ele falou: 'a porta tá aberta'. Aí ela falou: 'Por que você tem olhos tão grandes?'. 'Pra te vê melhor'. 'Por que você tem uma boca tão grande?'. 'É::: pra pra pra te comer'. Aí ela foi lá e tava correndo, aí o caçador foi lá, tava ouvindo o grito e aí foi lá e matou o lobo e cortou, aí saiu a vó (ME - seis anos).

Todas as crianças demonstraram necessidade de feedback, evidenciando a escuta (exemplo 3 ).

\section{Exemplo 3 (diálogo):}

I - Ela teimou com a mamãe e passou e passou.

A mamãe falou: 'Porque lá por perto fica o lobo mau'. Aí ela teimou: 'Sim mamãe!'. E teimou com a mamãe e foi pelo caminho deserto.

$P$ - Hum!

I - E aí ela encontrou o lobo. O lobo falou bem assim, fingindo de anjinho: 'Posso ir com você?'. (I-cinco anos).

A importância da participação do adulto na narrativa pôde ser observada tanto nas histórias quanto nos relatos, mas de maneira distinta (Tabelas $3 \mathrm{e}$ 4). Na história, conforme o exemplo 3 , a criança sente necessidade de feedback, diferentemente do que ocorre nos relatos em que a necessidade é de diálogo.

Os dados evidenciam que o relato, como narrativa/monólogo, demora um pouco mais a aparecer do que a narrativa/história, pois, como pode ser observado no exemplo 4 , os relatos ocorreram predominantemente em situação de diálogo, o que leva a considerar que a maior parte das crianças pesquisadas ainda se encontra numa etapa anterior ao monólogo, nesse tipo de narrativa.

\section{Exemplo 4:}

$M-$ Eu fui viajar pra Niterói.

$P-E ́$ mesmo?

$M$ - Eu fui visitar a minha avó.

Tabela 3 - Ocorrência da necessidade de participação do adulto na narrativa de crianças com base em 50 histórias analisadas

\begin{tabular}{llc}
\hline Participação do adulto na narrativa & № & $\%$ \\
\hline Precisa introduzir a história & 12 & 24 \\
Precisa retomar algum fato para que a criança prossiga & 37 & 74 \\
Precisa ajudar quando é solicitado & 21 & 42 \\
Precisa dar feedback demonstrando interesse e atenção & 50 & 100 \\
Necessidade de mediação constante (sem monólogos) & 11 & 22 \\
\hline
\end{tabular}


Tabela 4 - Ocorrência da participação do adulto na narrativa de crianças com base em 50 relatos analisados

\begin{tabular}{lc}
\hline $\begin{array}{l}\text { Participação do adulto na } \\
\text { narrativa com perguntas } \\
\text { eliciadoras }\end{array}$ & № de vezes \\
\hline Onde? & 16 \\
Quem? & 25 \\
O quê? & 41 \\
Quando? & 3 \\
\hline
\end{tabular}

$P-E ́$ ? E como é que foi?

M - Foi irado. Foi legal. Ela tem, 400 cães. Que até...(...)

$P-O$ quê?

$M$ - Ela tem mais que dez cães. Tem dois papagaiozinhos, tem quatro cachorros que...que morde e tem um gatinho que se chama ceguinho e outro palhacinho. Ele é muito legal e eu adoro ele porque ele tem (...).

Nos relatos, os achados indicaram o que já havia sido observado na narrativa de histórias, isto é, as crianças pesquisadas não apresentaram nenhum problema quanto à elaboração de espaço, tempo e causalidade nos relatos (exemplo 5). Aliás, o desempenho dessas noções no relato pode ser mais bem percebido do que nas histórias (Tabela 5). $\mathrm{O}$ desempenho apresentado das amostras permitiu verificar que, no geral, essas crianças se encontram organizadas em relação ao tempo, espaço e relações causais, pois elas mostraram-se capazes de ordenar os eventos numa sucessão temporal com compreensão dos vínculos causais, ou seja, as justificativas apresentadas são coerentes.

\section{Exemplo 5:}

Quando eu era pequena, estudava na Uirandê. Tinha duas cadeirinhas do ursinho, aí a gente andava, né? Só que agora a gente já cresceram, não precisa mais. A gente...quando a gente tá em Vitória, a gente não bota o cinto, quando tá, aí... quando chegou na estrada de Vitória a gente bota o cinto e vai lá pra Mimoso ( $J$ - cinco anos).

Em ambos os casos, história e relato, o resultado foi o mesmo. As 50 crianças analisadas demonstraram dominar satisfatoriamente a relação temporal entre eventos. O operador narrativo "aí" também aparece com frequência, mas com uma diferença numérica acentuada, sendo utilizado 551 vezes na história e 152 vezes no relato. Infere-se que seja pelo fato de que a história ocorreu mais em situação de monólogo, o que explica a utilização em maior número de "aí", pois, na maioria das vezes, esse operador funciona na manutenção da dependência temporal atuando também como organizador da sequência narrativa. Como os relatos aconteceram, em sua maioria, em situação de diálogo, participação do interlocutor e a própria sequência de turnos,

Tabela 5 - Ocorrência da utilização de pontos de referência para localização temporal com base em 50 relatos analisados e quantidade de crianças

\begin{tabular}{lcc}
\hline Pontos de referência localização temporal & № de vezes & № de crianças \\
\hline Dormir & 10 & 6 \\
Acordar & 1 & 1 \\
Alimentar-se & 6 & 2 \\
Tomar banho & 4 & 2 \\
Fiquei um mês & 1 & 1 \\
Foi no terceiro período & 1 & 1 \\
Quando eu fizer sete anos & 1 & 1 \\
Quando eu era pequena & 1 & 1 \\
No dia em que & 1 & 1 \\
Outro dia & 3 & 3 \\
Antes & 2 & 2 \\
Era domingo & 1 & 1 \\
Um dia & 1 & 1 \\
Era 31 de agosto & 1 & 1 \\
Todo dia & 1 & 1 \\
\hline
\end{tabular}


favorece a progressão da narrativa sem a necessidade de ocorrência de tantos operadores/conectivos. O "depois" ocorreu 92 vezes nas histórias e 48 vezes nos relatos. Como já exposto, o "sabe" apareceu em maior número no relato, como para garantir o conhecimento do interlocutor sobre o que estava sendo contado ou ainda como forma de partilhar o assunto. Tanto nas histórias quanto nos relatos, o "quando" aparece utilizado com pertinência (exemplo 6), construindo ponto de referência para a localização temporal, geralmente concreta, do evento.

\section{Exemplo 6:}

F - Foi muito legal. Mas o parque, quando eu ia falar com alguém, eu tinha que falar em português. Mas eles não entendiam. A única coisa que eu sei falar é só um pouquinho de coisa.

$P$ - O que você sabe?

F-I love you, mommy, papy, yes, now e ...l love you e...

Comparando as histórias e os relatos das 11 crianças que demandaram maior nível de mediação na história, o resultado revelou que quatro delas precisaram de uma participação mais efetiva do interlocutor e as outras sete tiveram um desempenho semelhante ao das demais crianças.

Quanto aos elementos prosódicos, observou-se que, no relato, todas as crianças usaram um elemento assim como nas histórias. No entanto, notase que existem diferenças interessantes, observáveis. No relato, a entoação/prosódia é quase sempre mais voltada para a manutenção da atenção, como querendo dizer: "Veja quanta coisa interessante tenho para contar", vindo acompanhados de outros elementos não-verbais, como a ilustração de um evento narrado (dramatização), gestos corporais e o olhar vago, como que buscando a lembrança do momento vivido com carga emocional. $\mathrm{Na}$ história, esses elementos são mais exagerados, com mudanças de vozes, tons ascendentes e descendentes e voz de suspense.

As crianças, tanto nas histórias quanto nos relatos, demonstraram necessidade de feedback, "cobrando" do interlocutor algum sinal de escuta. As expressões "ah", "sei", "é?" e "e aí?" foram usadas em ambos os casos. Observa-se que a relação com o interlocutor se modifica de acordo com o tipo de narrativa a ser explicitada e com o seu desenvolvimento linguístico.

Perguntas eliciadoras, como Onde? Quem? O quê? Quando?, estiveram presentes tanto nas histórias quanto nos relatos (exemplo 7), porém de forma diferente. Nas histórias, elas ocorreram quando a criança precisou de mediação para a narrativa; no relato, na maior parte das vezes, elas aparecem como solicitação de dados para a referência do interlocutor (Tabela 4).

\section{Exemplo 7:}

$P$ - O que o lobo respondeu?

$P e$ - 'É pra mim te ver melhor'. 'Por que esse nariz tão grande vovó?'. 'É pra mim te cheirar melhor!'. 'Pra que essa orelha tão grande vovó?'. 'Pra mim te ouvir melhor!'. 'Pra que essa boca tão grande vovó?'. ' Pra mim te come!'. Ela ... ela chamou o caçador que matou o lobo e tirou a vovó.

$\mathrm{Pe}-\mathrm{O}$ lobo... aí ele encheu de pedra a barriga do lobo. O caçador e aí eles foram embora.

$P$ - Quem foi embora?

Pe - o caçador.

\section{DISCUSSÃO}

O presente estudo evidencia que $82 \%$ das crianças têm bom domínio da estrutura da narrativa, necessitando de pouca mediação na narrativa de histórias. As histórias parecem fazer parte do dia-adia dessas crianças.

Um grupo de crianças fez uma narrativa inicial, necessitando depois da mediação do interlocutor em alguns momentos; e as crianças que precisaram da mediação ao longo da história tiveram monólogos em alguns momentos da narrativa.

Esse achado corrobora estudos anteriores ${ }^{9}$ que apontam que o diálogo figura cronologicamente em primeiro lugar numa partilha da atividade de verbalização: um coloca questões, o outro responde, ou então, um introduz uma preposição e o outro aprova, recusa, acrescenta ou modaliza. Ao contrário, ser capaz de monologar, por exemplo, numa narrativa, é fazer outra coisa que encadear frases: é também a capacidade de organizar o 'isto é para dizer', 'isto é para não dizer' ou 'tendo dito isso, eu posso (ou eu devo) dizer aquilo' 7 .

Estudos ${ }^{16}$ apontam a narrativa como uma tarefa neurocognitiva que envolve uma multiplicidade de funções executivas, linguísticas, atencionais, mnésicas e afetivas; e há de se considerar que nesse estudo também foi possível observar que narrar serve às necessidades cognitivas, estruturando $e$ processando a experiência pessoal e as necessidades sociais, compartilhando experiências ${ }^{15,20,22}$.

Tanto nos relatos quanto na narrativa de histórias, as crianças pesquisadas não apresentaram nenhum problema quanto à elaboração de espaço, tempo e causalidade nos relatos. O desempenho apresentado das amostras permitiu verificar que, no geral, essas crianças se encontram organizadas em relação ao tempo, espaço e relações causais, pois elas mostraram-se capazes de ordenar os eventos 
numa sucessão temporal com compreensão dos vínculos causais, ou seja, as justificativas apresentadas são coerentes.

Os resultados corroboram estudos ${ }^{9,18,22-25}$ que indicam que as crianças evoluem da elaboração de uma lista de ações temporalmente desorganizadas até a elaboração de narrativas que seguem a sequência temporal dos eventos, mas terminam abruptamente no ponto culminante da história e que o padrão clássico de história aumenta com a idade e este padrão é mais comum aos seis anos. Isso também pode ser observado nesse estudo apesar da pequena variação na idade das crianças pesquisadas, lembrando ainda que as diferenças individuais também devam ser levadas em consideração, pois elas influem na produção narrativa.

O operador narrativo "aí" e "depois" apresentase como sequenciador de episódios exprimindo, dentro deles, relações semânticas como tempo, causa, sequência. Nota-se, no entanto, um enriquecimento vocabular gradual nas narrativas em que essas relações aparecem.

Nas narrativas analisadas, de maneira geral, predominaram os verbos de ação e os tempos verbais que orientaram as narrativas são o pretérito perfeito e o imperfeito. Tais verbos configuram uma situação narrativa e orienta no mundo narrado as coisas distantes, não imediatas.

No contexto da interação é consenso entre os sociointeracionistas a importância do adulto no desenvolvimento das habilidades narrativas e os resultados da pesquisa corroboram todos os estudos que evidenciam que os adultos exercem papel central na construção da linguagem e dos gêneros discursivos das crianças ${ }^{9,13,14,18-20}$. O adulto colabora ao compartilhar noções de relevância narrativa; alocar turnos narrativos; suportar ou questionar a validade da história e da performance da criança e fazer perguntas eliciadoras.

\section{CONCLUSÃO}

Esta pesquisa teve como objetivo analisar aspectos constitutivos das narrativas de histórias e relatos em crianças de 5 e 6 anos e acredita-se ter cumprido o objetivo proposto.

Após a análise, pode-se afirmar que as crianças apresentaram maior facilidade na produção da história que no relato; responderam a todo tipo de pergunta eliciadora; a maior parte precisou de mediação apenas no relato; respeitaram a sequência temporal tanto na história, usando as figuras da história de maneira correta, quanto no relato e utilizaram principalmente o "aí" como elemento de coesão causal e temporal.

Quanto à análise do sistema de categorias para a narrativa de histórias, conclui-se que as crianças pesquisadas encontram-se entre as categorias IV e V.

Torna-se importante enfatizar que a competência linguística oral e, em especial, a narrativa desenvolvida na relação com os adultos e na interação social, de modo geral, é ponto de partida para a construção da escrita.

\section{ABSTRACT}

Purpose: to analyze composing aspects of verbal narratives of 5 and 6-year-old children. Methods: 50 children took part in this research. There were 23 boys and 27 girls in pre-school classes of four private schools in Praia do Canto, an upper class neighborhood of Vitoria, Espirito Santo. The sample is composed of a verbal narrative of a story and personal account in a formal interaction in which the child was asked to tell the story Little Red Riding Hood, as it is a well-known story, and make a personal narrative. The analysis criteria were based on Perroni (1992) and Brandão \& Spinillo (2001). Results: the analyzed group displayed knowledge of narrative structures; satisfactory domain of temporal relations in narrated events; use of clauses which express temporal dependence with action verbs in past tenses; use of connectors with the predominance of "aî" (a colloquial form similar to then) and "depois" (after that); proper use of time and space reference points; well-organized space-time relations and causative relations being developed. The study also pointed out the importance of the participation of an interlocutor in structuring the narratives. Conclusion: the children showed more ease in structuring the story rather than the personal narrative; they answered all kinds of eliciting questions; most of them needed mediation only in the personal narrative; they followed the time sequence not only in the story, using correctly the story-related flashcards, as for the personal narrative, they use "aí" as the main connector for causative and temporal cohesion.

KEYWORDS: Narratives; Story; Language; Child 


\section{REFERÊNCIAS}

1. Labov W, Waletzky J. Narrative analysis: oral versions of personal experience. In: Helm J, organizador. Essays on the verbal and visual arts. Seattle: University of Washington Press; 1967. p.12-44.

2. Mousinho R. Desenvolvimento da leitura e escrita e seus transtornos. In: Goldfeld M. Fundamentos em fonoaudiologia: linguagem. 2. ed. Rio de Janeiro: Guanabara Koogan; 2003. p. 39-59.

3. McCartney E. Developmental issues: speaking and phonological awareness. In: Lewis M, Ellis S, organizador. Phonics: practice, research and policy. London: Paul Chapman Publishing/UKLA; 2006. p.71-82.

4. McCabe A, Peterson C. Getting the story: a longitudinal study of parental styles in eliciting narratives and developing narrative skill. In: McCabe A, Peterson C, organizador. Developing narrative structure. Hillsdale: Lawrence Erlbaum Associates; 2001. p. 217-54.

5. Miilher LP, Ávila CRB. Variáveis lingüísticas e de narrativas no distúrbio de linguagem oral e escrita. Pró-Fono. 2006; 18(2):177-88.

6. Motta AB, Enumo SRF, Rodrigues MMP, Leite L. Contar histórias: uma proposta de avaliação assistida da narrativa infantil. Inter Psicol. 2006; 10(1):157-67.

7. Melo LE. A narrativa como um passaporte para a entrada da criança na escrita. [livre docência] São Paulo (SP): Universidade de São Paulo; 2001.

8. Gomes HS. Narrativas infantis: contribuição para a autoria da criança. [dissertação] São Paulo (SP): Universidade de São Paulo; 2005.

9. Perroni MC. Desenvolvimento do discurso narrativo. São Paulo: Martins Fontes; 1992. 235 p.

10. Price JR, Roberts JE, Jackson SC. Structural development of the fictional narratives of African American preschoolers. Lang Speech Hear Serv Schools. 2006; 37(3):178-90.

11. Smith VH, Sperb TM. The construction of the narratorsubject: discoursive thoughtinthe personalist stage. Psicol Estud. 2007; 12(3):553-62.

DOI: 101590 / S1516 - 18462009005000013

RECEBIDO EM: 26/02/2008

ACEITO EM: 23/09/2008

Endereço para correspondência:

Eliane Varanda Dadalto

Rua Constante Sodré, 750 sala 1106

Vitória - ES

CEP: 29055-420

E-mail: elianedadalto@yahoo.com.br
12. Shiro M. Genre and evaluation in narrative development. J Child Lang. 2003; 30(1):165-95.

13. Hudson JA. The development of future time concepts through mother-child conversation. MerrillPalmer Quarterly. 2006; 52(1):70-95.

14. Peterson C, Roberts C. Like mother, like daughter: similarities in narrative style. Develop Psychol. 2003; 39(3):551-62.

15. Klapproth D. Narrative as social practice: AngloWestern and Australian aboriginal oral traditions. Bern: Mouton de Gruyter; 2004.

16. Justice LM, Bowles RP, Kaderavek JN, Ukrainetz TA, Eisenberg SL, Gillam RB. The index of narrative microstructure: a clinical tool for analyzing schoolage children's narrative performances. Am J Speech-Lang Path. 2006; 15(2):177-91.

17. Bastos L. Contando estórias em contextos espontâneos e institucionais: uma introdução ao estudo da narrativa. Caleidoscópio. 2005; 3(2):74-87.

18. Peterson C, McCabe A. Echoing our parents: parental influences on children's narration. In: Pratt $\mathrm{MW}$, Fiese BE, organizador. Family stories and the lifecourse: across time and generations. Mahwah, NJ: Erlbaum: Allyn \& Bacon; 2004. p. 27-54.

19. Becker T. The role of narrative interaction in narrative development. In: Quasthoff UM, Becker T, organizador. Narrative interaction. Amsterdam \& Philadelphia: John Benjamins; 2005. p. 93-112.

20. McCabe A, Peterson C, Connors DM. Attachment security and narrative elaboration. Int $\mathrm{J}$ Behav Develop. 2006; 30(5):398-409.

21. Silva MEL, Spinillo AG. A influência de diferentes situações de produção na escrita de histórias. Psicol Reflex Crit. 2000; 13(3):337-50.

22. Spinillo AG, Rego FB, Lima EB, Souza N. A aquisição da coesão textual: uma análise exploratória da compreensão e da produção de cadeias coesivas. In: Spinillo G, Carvalho AG, Avelar $\mathrm{T}$, organizador. Aquisição da linguagem: teoria e pesquisa. Recife: Editora da Universidade Federal de Pernambuco; 2002. p.71-100.

23. Meirelles V, Spinillo AG. Uma análise da coesão textual e da estrutura narrativa em textos escritos por adolescentes surdos. Estud Psicol. 2004; 9(1):131-44.

24. Brandão ACP, Spinillo AG. Produção e compreensão de textos em uma perspectiva de desenvolvimento. Est Psicol. 2001; 6(1):51-62.

25. Blum-Kulka $S$. Modes of meaning making in young children's conversational storytelling In: Thornborrow J, Coates J. The sociolinguistics of narrative. Amsterdam / Philadelphia: John Benjamins; 2005. p. 149-70. 